\title{
Reactive oxygen species modulate growth of cerebral aneurysms: a study using the free radical scavenger edaravone and p47phox ${ }^{-/-}$mice
}

\author{
Tomohiro Aoki, Masaki Nishimura, Hiroharu Kataoka, Ryota Ishibashi, Kazuhiko Nozaki and Nobuo Hashimoto
}

Cerebral aneurysm (CA) is a relatively common disease and can cause a catastrophic subarachnoid hemorrhage with a high mortality and morbidity rate. Despite its clinical and social importance, the detailed mechanism of CA formation remains to be elucidated, resulting in the absence of effective medical treatment against CAs. Recent studies revealed that chronic inflammation in arterial walls by hemodynamic force is implicated in CA formation. Reactive oxygen species (ROS) are a major mediator of inflammation and actively participate in the pathogenesis of various vascular diseases. In the present study, we first assessed the expression of ROS-producing and -eliminating genes in CA walls by immunohistochemistry and RT-PCR analysis. The ROS-producing gene, p47phox, was upregulated in infiltrating macrophages and medial smooth muscle cells in arterial walls. Upregulated ROS-producing genes and suppressed ROS-eliminating genes suggested that ROS overproduction occurred in aneurysmal walls. In situ superoxide imaging by dihydroethidium, which showed ROS overproduction in aneurysmal walls, confirmed this hypothesis. Edaravone, a powerful free radical scavenger, effectively inhibited CA formation by suppressing inflammation-related gene expression in aneurysmal walls. Furthermore, CA formation was markedly inhibited by p47phox deletion in mice and was accompanied by decreased inflammation in aneurysmal walls. These data suggested the active participation of ROS and p47phox in CA formation and the therapeutic potential of an ROS-eliminating agent against CA formation.

Laboratory Investigation (2009) 89, 730-741; doi:10.1038/labinvest.2009.36; published online 20 April 2009

KEYWORDS: animal model; cerebral aneurysm; free radical scavenger; macrophage; p47phox; reactive oxygen species

Subarachnoid hemorrhage by rupture of saccular cerebral aneurysms (CAs) is a life-threatening disease with a 30-day mortality rate of $45 \%$ and mild-to-severe morbidity rate of $30 \% .{ }^{1,2} \mathrm{CA}$ is a relatively common disease with a prevalence ranging from 1 to $5 \%$ in a large autopsy series. ${ }^{3}$ Despite its clinical and public importance, the detailed mechanisms of the initiation, progression and rupture of CAs remain to be elucidated, resulting in the absence of effective medical treatment for CAs. Many patients with unruptured CAs are followed up without effective medical treatment. A small number of patients undergo invasive microneurosurgical clipping or coiling with a risk of complications. Clarification of the mechanisms underlying CAs is necessary and there is an urgent requirement for developing therapies to reduce the burden on public health.

An animal model of CA was developed in our institute in 1978 by Hashimoto et al. ${ }^{4}$ This model is a very useful tool for studying CAs because they are spontaneously induced without direct handling of cerebral arteries by induction of excessive hemodynamic stress at the arterial bifurcation site. Using this model we have clarified that CAs are induced as a result of chronic inflammation of the arterial walls mainly by infiltrating macrophages. ${ }^{5,6}$

Reactive oxygen species (ROS) are a major mediator of various inflammatory cascades and are responsible for the pathogenesis of various diseases including arteriosclerosis and abdominal aortic aneurysms. ROS is produced by macrophages and some other cells and is important in inflammatory responses and tissue destruction. As regards, CAs only restricted information has been elucidated and little is known about the function of ROS in CA formation. ROS is produced by enzymatic oxidation. One of the enzymes responsible for ROS production is a family member of the $\mathrm{NADPH}$ oxidases. NADPH oxidase is formed as an

Department of Neurosurgery, Kyoto University Graduate School of Medicine, Kyoto, Japan

Correspondence: Dr M Nishimura, MD, PhD, Department of Neurosurgery, Kyoto University Graduate School of Medicine, 54 Kawaharacho, Shogoin, Sakyo-ku, Kyoto 606-8507, Japan.

E-mail: masakins@kuhp.kyoto-u.ac.jp

Received 17 January 2009; revised 3 March 2009; accepted 10 March 2009 
aggregation of subunits, ${ }^{7,8}$ including p47phox, which is expressed mainly in neutrophils and macrophages. ${ }^{9,10}$ Macrophages are the main inflammatory cells in CA walls and are critical in CA formation, which suggests a function of p47phox in CA formation. ${ }^{5}$

We hypothesized that ROS and the ROS-producing gene, p47phox, participated in CA formation. In the present study, using previously established CA models in rats and mice, we first clarified the critical function of ROS in CA formation.

\section{MATERIALS AND METHODS}

\section{Induction of Experimentally Induced CAs}

Cerebral aneurysms were induced as previously described. ${ }^{11}$ After the induction of pentobarbital anesthesia $(50 \mathrm{mg} / \mathrm{kg}$, i.p.), the left carotid artery and posterior branches of the bilateral renal arteries were ligated at the same time with 10-0 nylon in 7-week-old male Sprague-Dawley rats (Oriental Bioservice, Osaka, Japan). Animals were fed a high-salt diet containing $8 \%$ sodium chloride and $0.12 \% \beta$-aminopropionitrile (Tokyo Chemical, Tokyo, Japan), an inhibitor of lysyl oxidase that catalyzes the cross-linking of collagen and elastin. Blood pressure was measured by tail-cuff method twice in each rat without anesthesia.

Three months after aneurysm induction, the anterior cerebral artery/olfactory artery (ACA/OA) bifurcation was stripped and observed under a light microscope after Elastica van Gieson staining. To evaluate the pathological changes occurring in the aneurysmal walls, we analyzed the degeneration of internal elastic lamina (IEL), the thinning of the medial smooth muscle cell layer and the aneurysm size. IEL was classified into the following three categories: continuous, fragmented and completely disappeared; and each category was designated as the score 0,1 and 2 , respectively. The thickness of the media was evaluated by the ratio of the minimal thickness of the media in aneurysmal walls to the thickness of the media in surrounding normal arterial walls. Aneurysm size was calculated as the mean of the maximal longitudinal diameter and the maximal transverse diameter.

Animal care and experiments complied with Japanese community standards on the care and use of laboratory animals.

\section{Immunohistochemistry}

Three months after CA induction, all rats were deeply anesthetized and perfused transcardially with $4 \%$ paraformaldehyde. As a control, age-matched male SpragueDawley rats were killed as described above. The ACA/OA bifurcation was stripped and embedded in OCT compound. Sections of $5 \mu \mathrm{m}$ were cut and mounted on silane-coated slides. After blocking with 5\% donkey serum (Jackson ImmunoResearch, Baltimore, MD, USA), primary antibodies were incubated for $1 \mathrm{~h}$ at room temperature followed by incubation with fluorescence-labeled secondary antibodies (FITC-conjugated donkey anti-rabbit IgG antibody, FITCconjugated donkey anti-goat IgG antibody, FITC- or Cy3-conjugated donkey anti-mouse IgG antibody (Jackson
ImmunoResearch)) for $1 \mathrm{~h}$ at room temperature. Then the slides were covered with Permafluor (Immunotech, Marseille, France) and excited for fluorescence by illumination through a fluorescence microscope system (BX51N-34-FL-1; Olympus, Tokyo, Japan).

The primary antibodies used in the present study were the following: rabbit polyclonal anti-p47phox (Santa Cruz Biotechnology, Santa Cruz, CA, USA), rabbit polyclonal antisuperoxide dismutase-1 (SOD-1; Santa Cruz Biotechnology), goat polyclonal anti-heme oxygenase-1 (HO-1; Santa Cruz Biotechnology), mouse monoclonal anti-8-hydroxy-2-deoxyguanosine (8-OHdG; Japan Institute for the Control of Aging, Shizuoka, Japan), rabbit polyclonal anti-monocyte chemoattractant protein-1 (MCP-1; Santa Cruz Biotechnology), rabbit polyclonal anti-vascular cell adhesion molecule1 (VCAM-1; Santa Cruz Biotechnology), rabbit polyclonal anti-CD68 (HyCult biotechnology, Uden, the Netherlands), mouse monoclonal anti-smooth muscle $\alpha$-actin (Lab Vision, Richmond, CA, USA), mouse monoclonal anti-nuclear factor- $\kappa \mathrm{B}(\mathrm{NF}-\kappa \mathrm{B})$ p65 subunit antibody that recognizes only the DNA-binding form of p65 (Chemicon, Temecula, CA, USA), mouse monoclonal anti-endothelial nitric oxide synthase (eNOS: Biomol Research Laboratories, PA, USA).

\section{Characterization of p47phox-Secreting Cells}

The number of CD68/p47phox double-positive cells was counted in one section under a microscope $(n=5)$. The number of smooth muscle $\alpha$-actin/p47phox double-positive cells and eNOS/p47phox double-positive cells was also counted in the serial sections. To identify each cell, we performed 4',6-diamino-2-phenylindole staining at the same time. The ratio of each double-positive cell to the total p47phox-positive cells was calculated.

\section{RNA Isolation and RT-PCR}

At 2 weeks, 1 month or 3 months after aneurysm induction, rats were killed as described above. Total RNA from the whole Willis ring was isolated using the RNeasy Fibrous Tissue Mini kit (Qiagen, Hilden, Germany). Extraction was performed according to the manufacturer's instructions. Total RNA was converted into cDNA using Sensiscript Reverse Transcriptase (Qiagen). PCR was performed using HotStar Taq polymerase (Qiagen). $\beta$-Actin was used as an internal control. The primer sets used were: $5^{\prime}$-caaggttatgttgtgggatgg- $3^{\prime}$ and $5^{\prime}$-ttgcctggttggtagagtgc- $3^{\prime}$ for NADPH oxidase p47phox subunit; $5^{\prime}$-gcttctgtcgtctccttgct- $3^{\prime}$ and $5^{\prime}$-gcc ttgtgtattgtccccata- $3^{\prime}$ for SOD-1; $5^{\prime}$-cacgcatatacccgctacctt- $3^{\prime}$ and $5^{\prime}$-gaaggcggtcttagcctctt- $3^{\prime}$ for $\mathrm{HO}-1 ; 5^{\prime}$-ggctggacttctc actctgc- $3^{\prime}$ and $5^{\prime}$-tcccgaaacgctacacttcc- $3^{\prime}$ for inducible nitric oxide synthase (iNOS); $5^{\prime}$-ctgataacctggatgcagtcgt- $3^{\prime}$ and $5^{\prime}$-ccagccagtccgatttga- $3^{\prime}$ for matrix metalloproteinase-2 (MMP-2); $5^{\prime}$-aagtccctcaccctcccaaaag- $3^{\prime}$ and $5^{\prime}$-aagcaatgctgt caccttccc- $3^{\prime}$ for $\beta$-actin. The procedure for PCR was: $95^{\circ} \mathrm{C}$ for $10 \mathrm{~min}$ followed by 40 cycles of $95^{\circ} \mathrm{C}$ for $15 \mathrm{~s}, 55^{\circ} \mathrm{C}$ for $15 \mathrm{~s}$ and $72^{\circ} \mathrm{C}$ for $30 \mathrm{~s}$. PCR products were separated by 
electrophoresis in $2 \%$ agarose gels. Densitometric analysis was performed on five independent experiments.

\section{In Situ Imaging of Superoxide}

Three months after aneurysm induction, rats $(n=6)$ were deeply anesthetized as described above. Immediately after perfusion of physiological saline, the ACA/OA bifurcation was stripped, embedded and frozen. Sections of $5 \mu \mathrm{m}$ were cut and mounted on silane-coated slides. Slides were incubated in $20 \mu \mathrm{mol} / \mathrm{l}$ dihydroethidium (Wako, Tokyo, Japan) for $1 \mathrm{~h}$ at $37^{\circ} \mathrm{C}$ in a moisture chamber. Differential interference contrast images were obtained with a $580 \mathrm{~nm}$ filter. The ACA/OA bifurcation from age-matched male Sprague-Dawley rats served as a control.

\section{Western Blotting}

Whole cell lysate from rat Willis ring was extracted using Complete Lysis-M (Roche, Indianapolis, IN, USA). Lysate $(15 \mu \mathrm{g})$ was used in each experiment. After electrophoresis, transfer to a PDVF membrane (Hybond-P; Amersham, Buckinghamshire, UK) and addition of ECL Plus blocking agent (Amersham), the sample was incubated with primary antibody (1:500, same as in immunohistochemistry) for $1 \mathrm{~h}$ at room temperature followed by incubation with horseradish-peroxidase-conjugated anti-rabbit IgG antibody (GE Healthcare, Buckinghamshire, UK). The signal was detected by chemiluminescent reagent (ECL Plus Western Blotting Detection System; GE Healthcare). $\alpha$-Tubulin served as an internal control. Densitometric analysis included five independent experiments.

\section{Knockout Mice and Induction of Experimentally Induced CAs in Mice}

p47phox ${ }^{-1-}$ mice, whose genetic background was C57/B6, were purchased from Jackson Laboratory (Bar Harbor, ME, USA). When 7 weeks old, CAs were induced in them as previously described. ${ }^{12}$ Briefly, the left common carotid artery was ligated under general anesthesia using fluothane. After 1 week, the posterior branches of the bilateral renal artery were ligated. Animals were fed the same food as in the rat CA model. Blood pressure was measured by the tail-cuff method as in rats.

Five months after aneurysm induction, mice were killed and frozen sections were prepared as described above. This time course and CA formation in a mouse model were described in our previous report. ${ }^{13}$ After Elastica van Gieson staining, aneurysm formation at the ACA/OA bifurcation was assessed under a light microscope. Aneurysm size was measured as described for the rats. Some mice were subjected to immunohistochemistry. The detailed methods and antibodies used were the same as previously described.

\section{Free Radical Scavenger Treatment}

For further evaluation of the effect of free radicals, we used the free radical scavenger edaravone: 3-methyl-1-phenyl-2- pyrazolin-5-one (Mitsubishi Pharma Corporation, Osaka, Japan). Edaravone, $100 \mathrm{mg} / \mathrm{kg}$ per day was orally administered, starting just after aneurysm induction in rats. Control rats were fed the same food without edaravone. The dose was decided from previous preliminary studies in vivo and in vitro for adequate inhibition of production of free radicals. $\mathrm{IC}_{50}$ of edaravone for inhibition of production of free radicals was $6.7 \mu \mathrm{M}$ and, after oral administration of edaravone $100 \mathrm{mg} / \mathrm{kg}$ per day, the serum concentration of edaravone was $63.1 \pm 34.8 \mu \mathrm{M}$ by HPLC $(n=3)$. Three months after aneurysm induction, rats were killed as described above. Aneurysm formation was evaluated as already described.

\section{Calculation of Macrophage Infiltration}

Macrophages were defined as CD68-positive cells in immunohistochemistry. The number of infiltrating macrophages was calculated by counting the CD68-positive cells in a $10000 \mu \mathrm{m}^{2}$ around the dome of the ACA/OA aneurysms in rats and in a $2500 \mu \mathrm{m}^{2}$ in mice.

\section{Statistical Analysis}

Data (mean \pm s.d.) were analyzed by the Mann-Whitney $U$-test for a two-group comparison and Kruskal-Wallis one-way ANOVA by ranks followed by the Tukey-Kramer test for a multiple comparison. The incidence of aneurysmal changes was analyzed by the use of Fisher's exact test. Differences were considered statistically significant at $P<0.05$.

\section{RESULTS}

\section{Superoxide Production in CA Walls of Rats}

Superoxide production assessed by dihydroethidium staining dramatically increased in CA walls compared to control arterial walls (Figure $1 \mathrm{c}$ and $\mathrm{d}$ ) in rats. The oxidative product of DNA induced by ROS, 8-OHdG, also increased in aneurysmal walls in immunohistochemistry (Figure 1a and b).

\section{Expression of ROS-Related Genes during Aneurysm Progression in Rats}

NADPH p47phox mRNA expression significantly increased during CA progression ( $0 \mathrm{M}$ vs $0.5 \mathrm{M}: P=0.030,0.5 \mathrm{M}$ vs $1 \mathrm{M}$ : $P<0.01, n=5$ ) (Figure $2 \mathrm{a}$ and $\mathrm{b}$ ) in RT-PCR. iNOS expression and MMP-2 expression increased 2 weeks after aneurysm induction and were maintained at a high level during CA progression. HO-1 expression gradually increased over 1 month after aneurysm induction but, after 3 months, the expression decreased to its initial level. SOD-1 expression significantly decreased during CA progression (Figure 2a). Immunostaining of p47phox was absent in control arterial walls but was increased 1 and 3 months after aneurysm induction in aneurysmal walls (Figure $3 \mathrm{~d}-\mathrm{f}$ ). In western blots, p47phox expression was upregulated 3 months after aneurysm induction ( 1 month $v s 3$ months: $P<0.01, n=5$ ) (Figure $3 \mathrm{~m}$ and $\mathrm{n}$ ) coinciding with the results of immunohistochemistry. Immunostaining showed SOD-1 abundantly present mainly in the media of control arterial walls and it 
0M
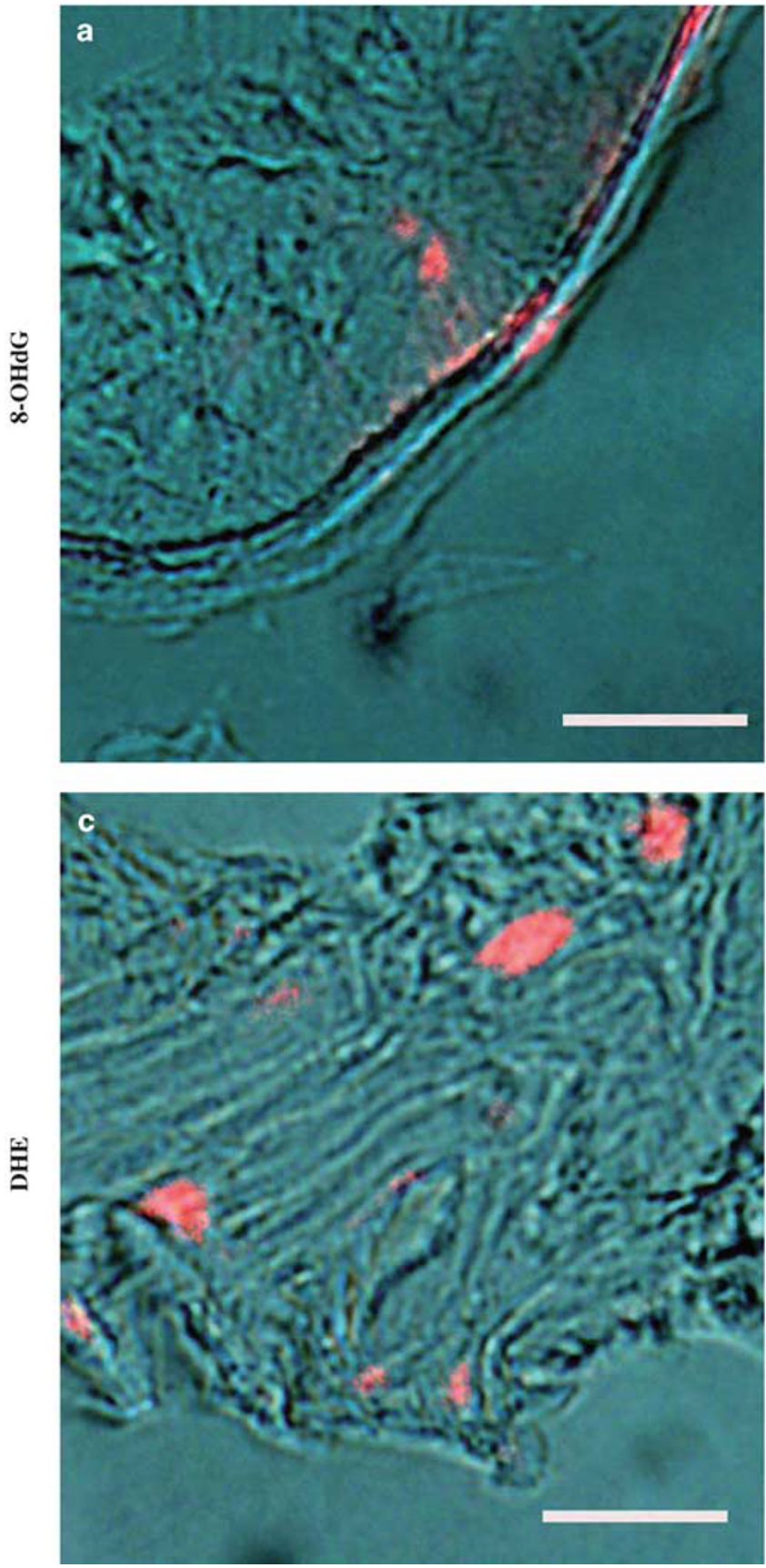

$3 \mathrm{M}$
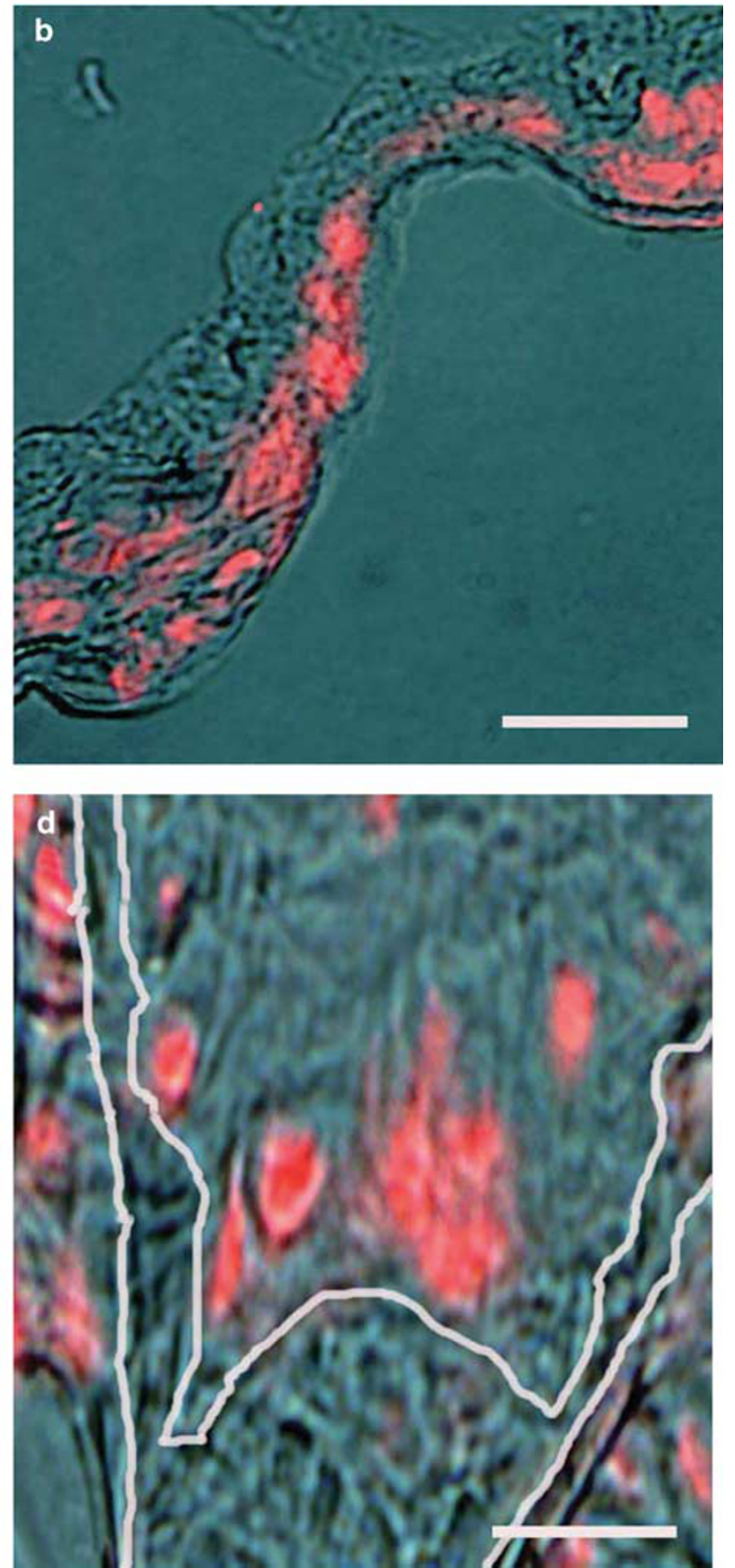

Figure 1 ROS production in aneurysmal walls in rats. (a-d) Immunostaining of 8-OHdG (a and $\mathbf{b})$ and in situ detection of superoxide by dihydroethidium (c and $\mathbf{d}$ ) in rats 3 months after aneurysm induction (3M) (b and $\mathbf{d}$ ) and in control rats (OM) (a and $\mathbf{c})$. Bar $=20 \mu \mathrm{m}$.

gradually decreased during aneurysm progression (Figure $3 \mathrm{~g}-\mathrm{i})$. Immunostaining of $\mathrm{HO}-1$ was only weak in control arterial walls but markedly increased 1 month after aneurysm induction. Three months after aneurysm induction, expression of HO-1 was weaker than 1 month after aneurysm induction (Figure 3j-1). The expression pattern of these molecules was consistent with mRNA expression.

\section{Characterization of p47phox-Expressing Cells in Aneurysmal Walls in Rats}

The main p47phox-expressing cells in aneurysmal walls of rats were macrophages and smooth muscle cells (endothelial cell (EC): $9.7 \pm 7.1 \%$, macrophage: $53.1 \pm 5.1 \%$, smooth muscle cell: $38.2 \pm 6.7 \%$, EC vs macrophage: $P<0.01$, EC vs smooth muscle cells, $P<0.01, \quad n=5)$. Almost all 
macrophages expressed the p47phox subunit $(91.3 \pm 8.1 \%$, $n=5$ ) (Figure 4) in immunohistochemistry.

\section{CA Formation in p47phox ${ }^{+1+}$ and p47phox ${ }^{-1-}$ Mice} In $\mathrm{p} 47 \mathrm{phox}^{-1-}$ mice, immunostaining of $\mathrm{p} 47 \mathrm{phox}$ was absent (Figure $5 \mathrm{j}$ ). The size of the induced CAs was significantly smaller in $\mathrm{p} 4 \mathrm{phox}^{-1-}$ mice than $\mathrm{p} 47 \mathrm{phox}^{+1+}$ mice $\left(\right.$ p47phox ${ }^{+/+}: \quad 25.0 \pm 27.0 \mu \mathrm{m}, \quad n=14 ; \quad \mathrm{p}^{2} 7 \mathrm{phox}^{-/-}$: $7.0 \pm 11.8 \mu \mathrm{m}, n=10 ; P=0.044$ ) (Figure 5a). After aneurysm induction, systemic blood pressure significantly increased but there was no difference between $\mathrm{p} 47 \mathrm{phox}^{+1+}$ and $\mathrm{p} 47 \mathrm{phox}^{-1-}$ mice (0M: p47phox ${ }^{+/+}$mice: $90.5 \pm 17.7 \mathrm{mmHg}, \quad n=10$;

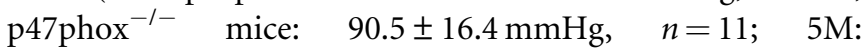

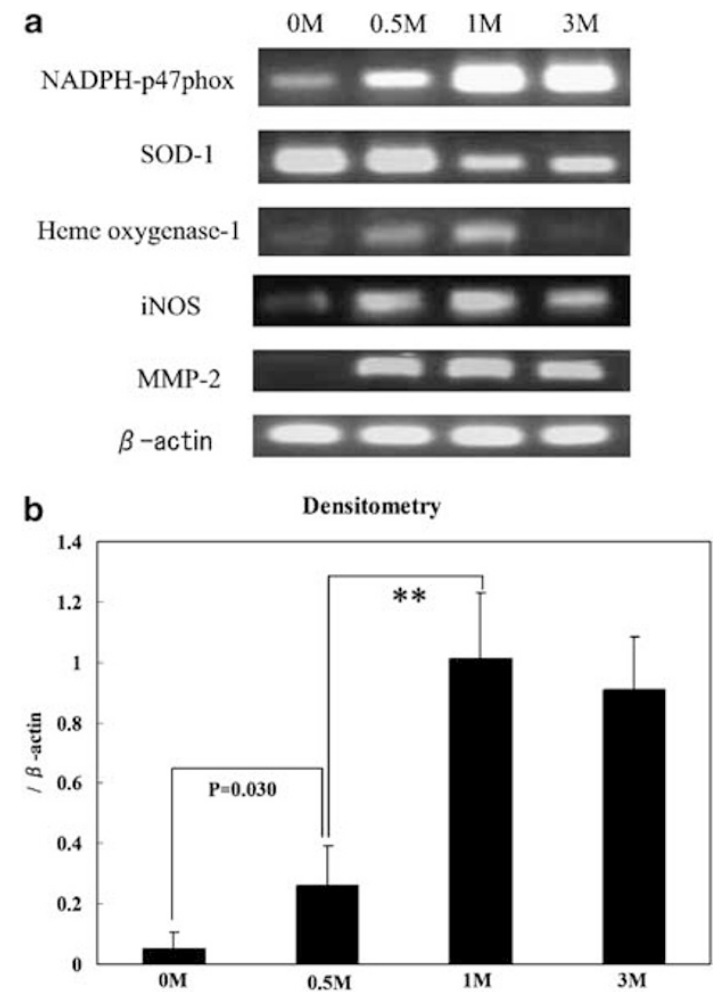

Figure 2 Expression of ROS-related genes in RT-PCR. (a) Representative images of RT-PCR from five independent experiments. $\beta$-Actin was used as an internal control. (b) Densitometric analysis of NADPH oxidase p47phox mRNA $(n=5)$. Data were analyzed by Kruskal-Wallis one-way ANOVA by ranks followed by the Tukey-Kramer test. ${ }^{*} P<0.01$. $0 \mathrm{M}$ : before aneurysm induction, $0.5 \mathrm{M}$ : 2 weeks after aneurysm induction, $1 \mathrm{M}: 1$ month after aneurysm induction, 3M: 3 months after aneurysm induction. p47phox ${ }^{+/+}$mice: $133.2 \pm 12.0 \mathrm{mmHg}, n=10$; $47 \mathrm{phox}^{-/-}$ mice: $138.4 \pm 15.2 \mathrm{mmHg}, n=11$ ) (Figure $5 \mathrm{~b}$ ). A representative image of induced CAs in mice clearly demonstrated the effect of p47phox deficiency on CA formation (Figure $5 \mathrm{c}$ and d). Macrophage infiltration into aneurysmal walls was significantly inhibited in $\mathrm{p} 47 \mathrm{phox}^{-1-}$ mice compared to p47phox ${ }^{+/+}$mice $\left(\mathrm{p} 47\right.$ phox $^{+1+}$ mice: $3.7 \pm 1.5$ cells per $50 \mu \mathrm{m}, n=14$; 47 phox $^{-1-}$ mice: $1.8 \pm 1.3$ cells per $50 \mu \mathrm{m}$, $n=10 ; P<0.01$ ) (Figure 5e). In p47phox ${ }^{-1-}$ mice, immunostaining of 8 -OHdG was markedly reduced suggesting that ROS production was inhibited (Figure $5 \mathrm{~g}$ and $\mathrm{k}$ ). Immunostaining of the DNA-binding form of NF- $\kappa \mathrm{B}$ p65 subunit and MCP-1 was apparently inhibited in $\mathrm{p} 47 \mathrm{phox}^{-1-}$ mice (Figure 5h, i, l and $\mathrm{m}$ ).

\section{Effect of Edaravone, a Free Radical Scavenger, on CA Formation and Macrophage Infiltration into Aneurysmal Walls in Rats}

The size of induced CAs was significantly smaller in the edaravone-treated group than in the control group 3 months after aneurysm induction (control group: $71.2 \pm 24.5 \mu \mathrm{m}$, $n=21$; edaravone-treated group: $32.5 \pm 20.7 \mu \mathrm{m}, n=10$; $P<0.01$ ) (Figure 6a). Changes of IEL by scoring criteria, described in Materials and methods, were also significantly inhibited by edaravone treatment (control group: $1.47 \pm 0.51$, $n=21$; edaravone-treated group: $1.20 \pm 0.21, \quad n=10$; $P=0.043$ ) (Figure $6 \mathrm{~b}$ ). The thickness of the media was significantly greater in the edaravone-treated group than in the control group (control group: $0.44 \pm 0.20, n=21$; edaravonetreated group: $0.75 \pm 0.19, n=10 ; P<0.01$ ) (Figure $6 c$ ). Systemic blood pressure was significantly elevated 3 months after aneurysm induction both in control and edaravonetreated groups but there was no significant difference between the two groups (0M: $103.7 \pm 3.2 \mathrm{mmHg}, n=6$; $3 \mathrm{M}$ : control group: $170.6 \pm 14.6 \mathrm{mmHg}, \quad n=10$; edaravonetreated group: $163.6 \pm 16.7 \mathrm{mmHg}, n=11$ ) (Figure 6d). Representative images of induced CAs clearly demonstrated the effect of edaravone on CA formation such as the prevention of medial degeneration and IEL disruption (Figure 6e and f).

Macrophage infiltration into aneurysmal walls was significantly inhibited by edaravone treatment (control group: $5.0 \pm 2.6$ cells per $10000 \mu \mathrm{m}^{2}, n=21$; edaravone-treated group: $3.4 \pm 1.5$ cells per $10000 \mu \mathrm{m}^{2}, n=10 ; P=0.047$ ) (Figure 6g-i).

Figure 3 Expression of p47phox, SOD-1 and HO-1 in aneurysmal walls by immunohistochemistry and western blotting. Differential interference contrast images of the ACA-OA bifurcation in control rats (OM) (d, $\mathbf{g}$ and $\mathbf{j})$, rats 1 month after aneurysm induction (1M) (e, $\mathbf{h}$ and $\mathbf{k})$ and 3 months after aneurysm induction (3M) (f, i and I). (a-c) Elastica van Gieson staining. (d-f) p47phox staining (FITC: green) of the serial section of a. (g-i) Superoxide dismutase-1, SOD-1 ( FITC: green), staining of the serial section of $\mathbf{b}$. (j-I) Heme oxygenase-1, HO-1 (FITC: green), staining of the serial section of $\mathbf{c}$. Red color (Cy3) shows the expression of smooth muscle $\alpha$-actin. Bar $=30 \mu \mathrm{m}$. ( $\mathbf{m}$ and $\mathbf{n}$ ) Western blotting $(\mathbf{m})$ and densitometric analysis (n) of NADPH oxidase p47phox subunit. Representative images from five independent experiments are shown $(n=5)$. Data were analyzed by Kruskal-Wallis one-way ANOVA by ranks followed by the Tukey-Kramer test. ${ }^{*} P<0.01$. 

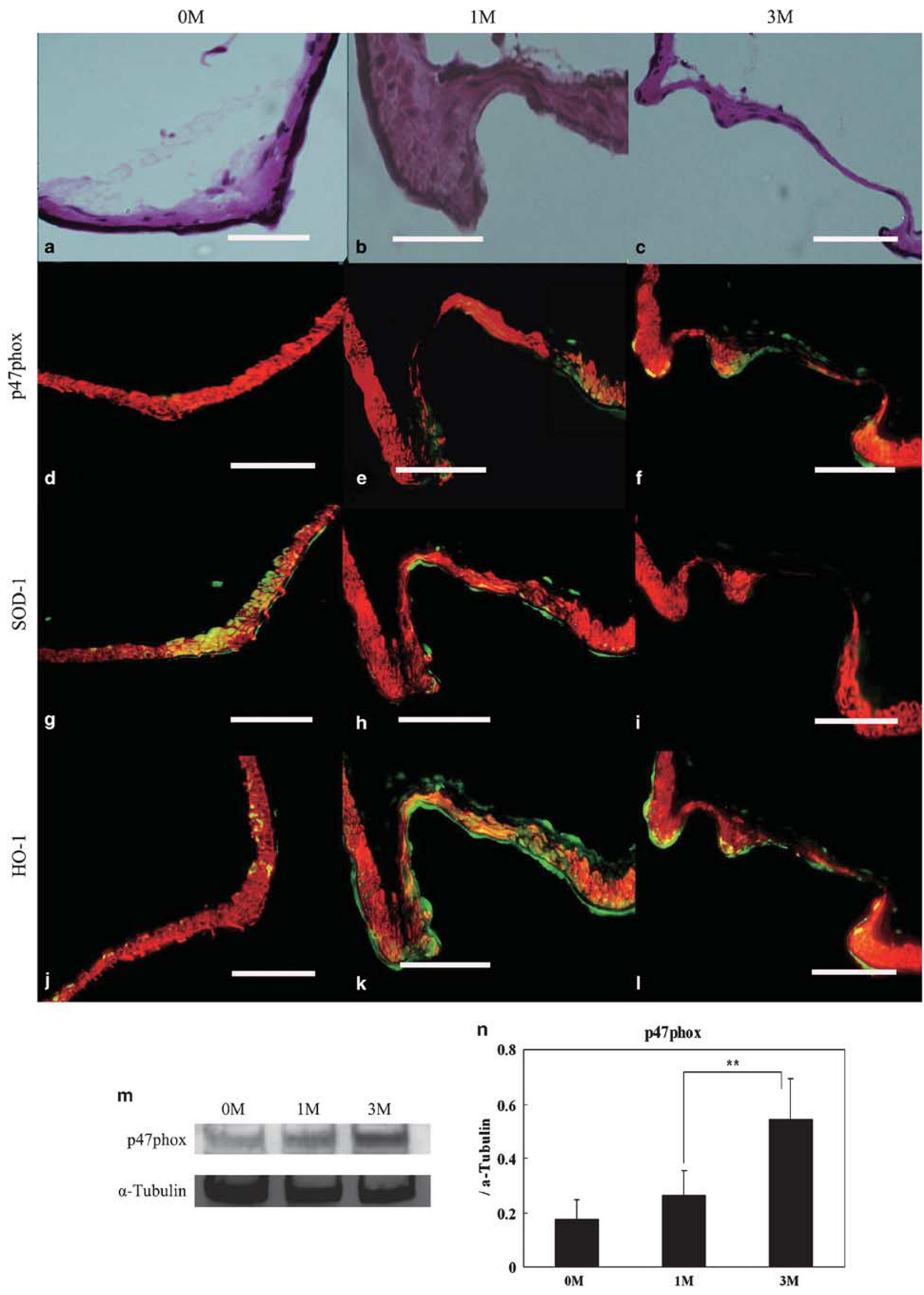

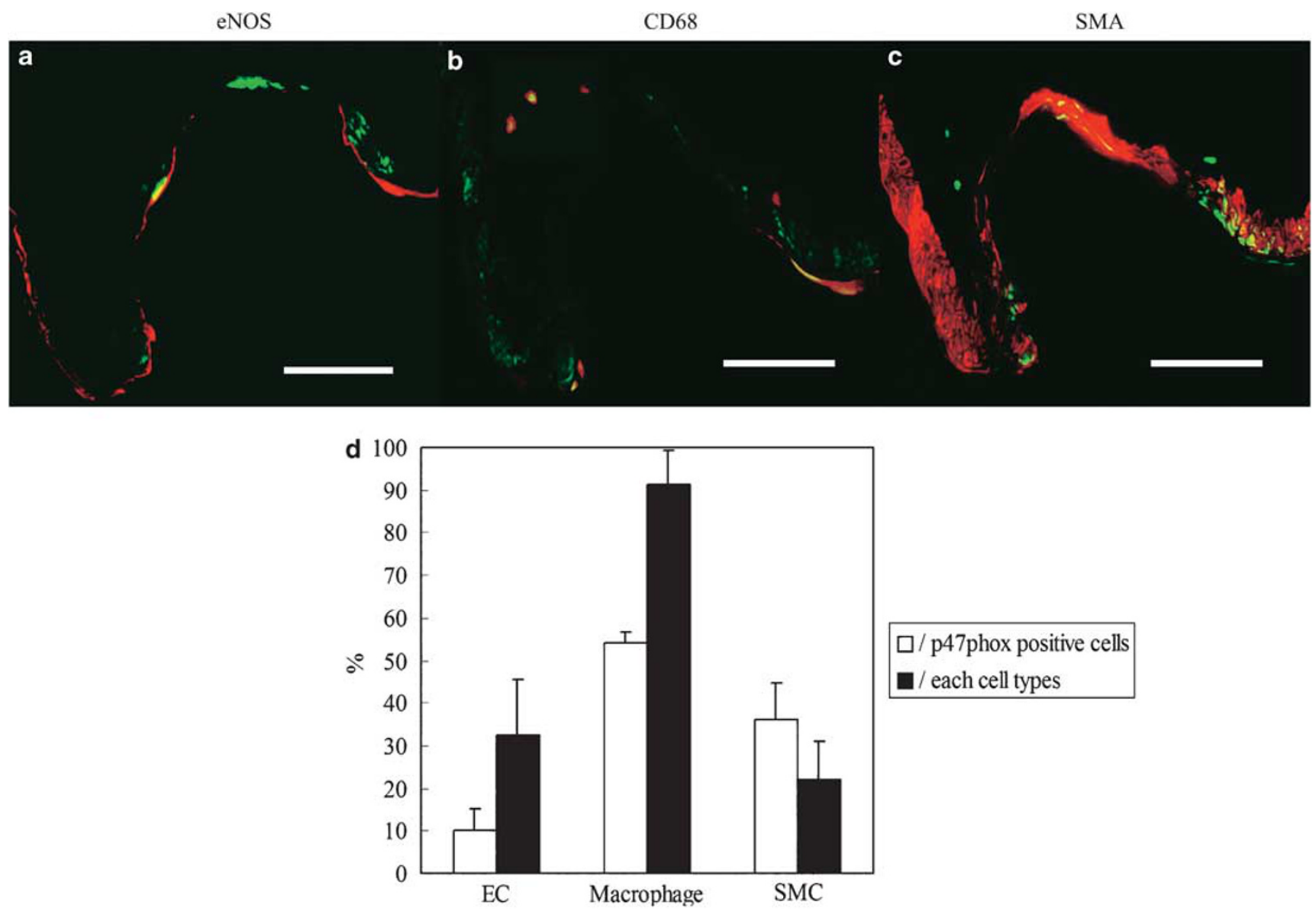

Figure 4 Characterization of p47phox-producing cells in aneurysmal walls. (a-c) Double staining of p47phox (FITC: green) and eNOS (Cy3: red) (a), p47phox (FITC: green) and CD68 (Cy3: red) (b), p47phox (FITC: green) and smooth muscle $\alpha$-actin, SMA (Cy3: red) (c). (d) The ratio of double-positive cells in the total p47phox-positive cells (white bar) or in each cell type (black bar) $(n=5)$. mean \pm s.d; EC, endothelial cell; SMC, smooth muscle cell. Bar $=20 \mu$ m.

\section{Effect of Edaravone on ROS Production and DNA Oxidation}

Superoxide production by dihydroethidium staining was markedly inhibited by edaravone treatment (Figure $7 \mathrm{c}$ and d). The number of 8-OHdG-stained cells in aneurysmal walls was significantly smaller in the edaravone-treated group than in the control group (control group: 12.8 \pm 3.6 cells per $10000 \mu \mathrm{m}^{2}, \quad n=5$; edaravone-treated group: $6.3 \pm 2.3$ cells per $10000 \mu \mathrm{m}^{2}, n=5 ; P=0.044$ ) (Figure $7 \mathrm{a}, \mathrm{b}$ and e).

\section{Effect of Edaravone on NF- $\kappa$ B p65, MCP-1, VCAM-1 and MMP-2 Expression}

Edaravone markedly inhibited the expression of the DNAbinding form of the NF- $\kappa$ B p 65 subunit, MCP-1, VCAM- 1 and MMP-2 in aneurysmal walls as shown by immunohistochemistry (Figure $7 \mathrm{f}-\mathrm{o}$ ).

\section{DISCUSSION}

In the present study, we clarified that ROS and macrophageexpressing ROS-producing enzyme NADPH oxidase p47phox is critical in CA formation. Furthermore, we suggest the possibility of medical treatment for CAs using the free radical scavenger edaravone.

Cerebral aneurysm has a high prevalence ranging from 1 to $5 \%$ in a large autopsy series. ${ }^{3}$ It can cause a catastrophic subarachnoid hemorrhage, which is a severe form of stroke, with a 30-day mortality rate of $45 \%$ and mild-to-severe morbidity rate of $30 \% .{ }^{1,2}$ Currently, treatment options for unruptured CAs are observation, microneurosurgical clipping and endovascular coil embolization. Many patients with small CAs, poor general condition or who have been refused surgical procedures are followed up with sequential radiological evaluation but with no options for medical treatment at present. We have only a restricted knowledge of the mechanisms of CA formation and progression, which is the main reason for the current treatment situation. To develop effective medical treatment, we used previously established CA models of rats ${ }^{4}$ and mice, ${ }^{12}$ and clarified some of the important mechanisms of CA formation and progression. $\mathrm{CA}$ is a chronic inflammatory disease in arterial walls triggered by excessive hemodynamic stress. We determined $\mathrm{NF}-\kappa \mathrm{B}$ as a critical mediator of CA formation by inducing 
a

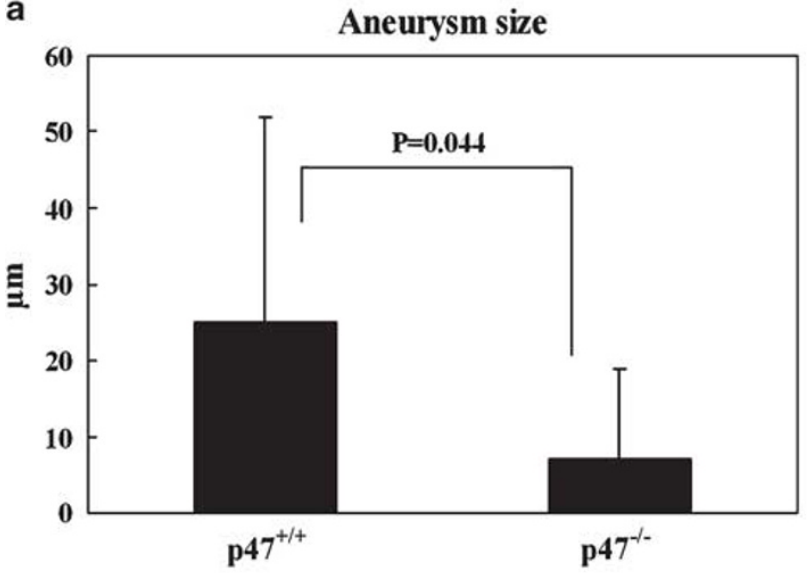

$\mathrm{p} 47^{+/+}$

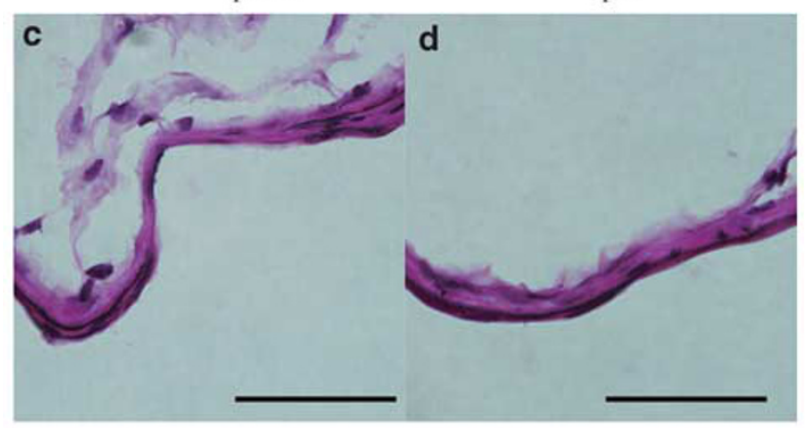

p47phox

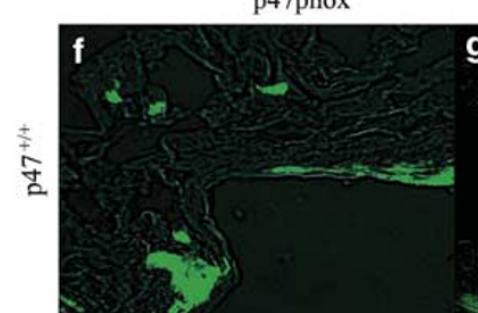

b

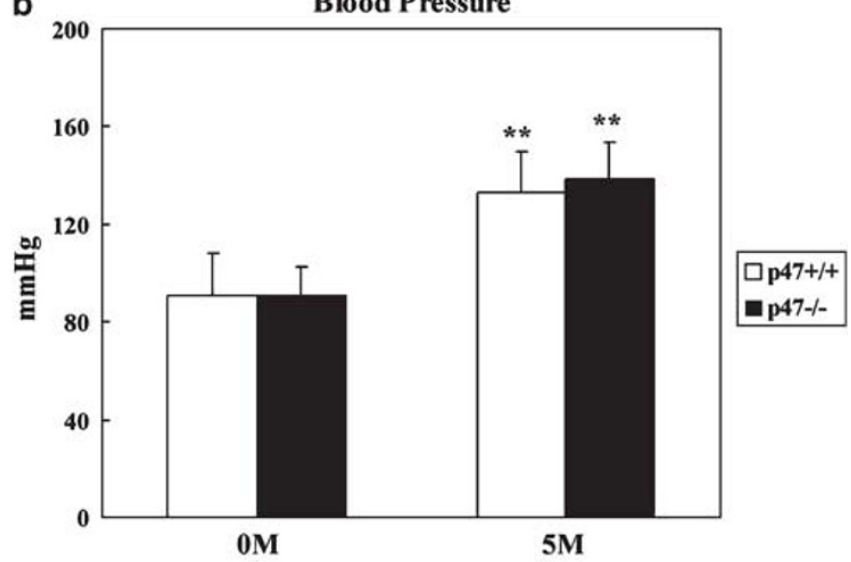

e

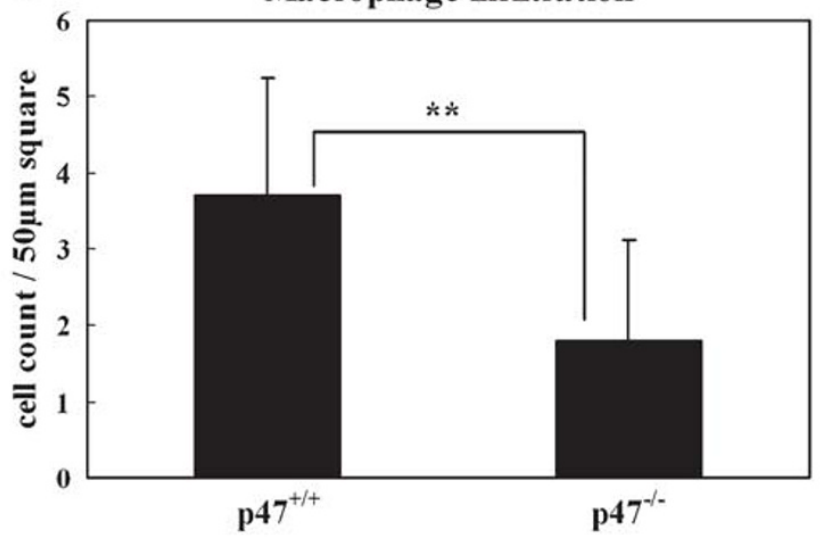

Macrophage infiltration

p65

MCP-1 h

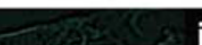
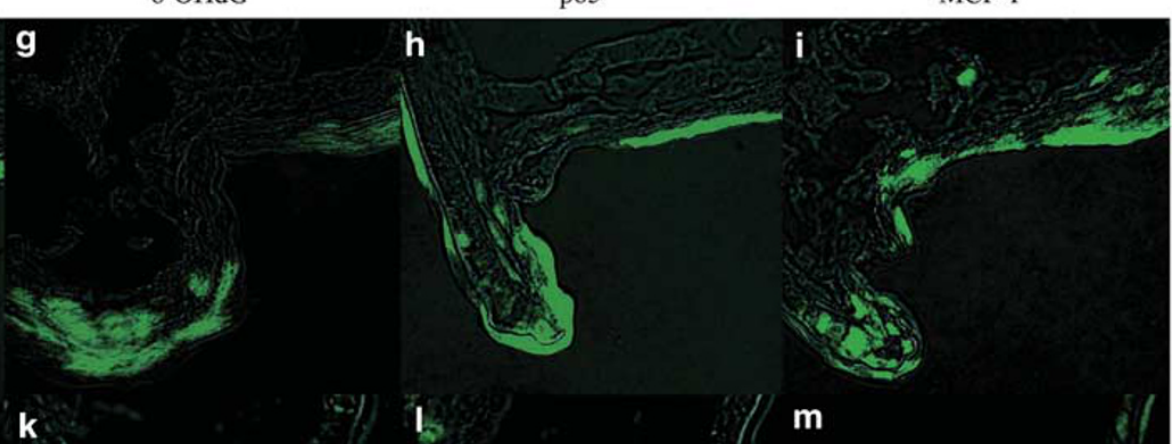

k
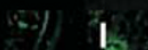

m
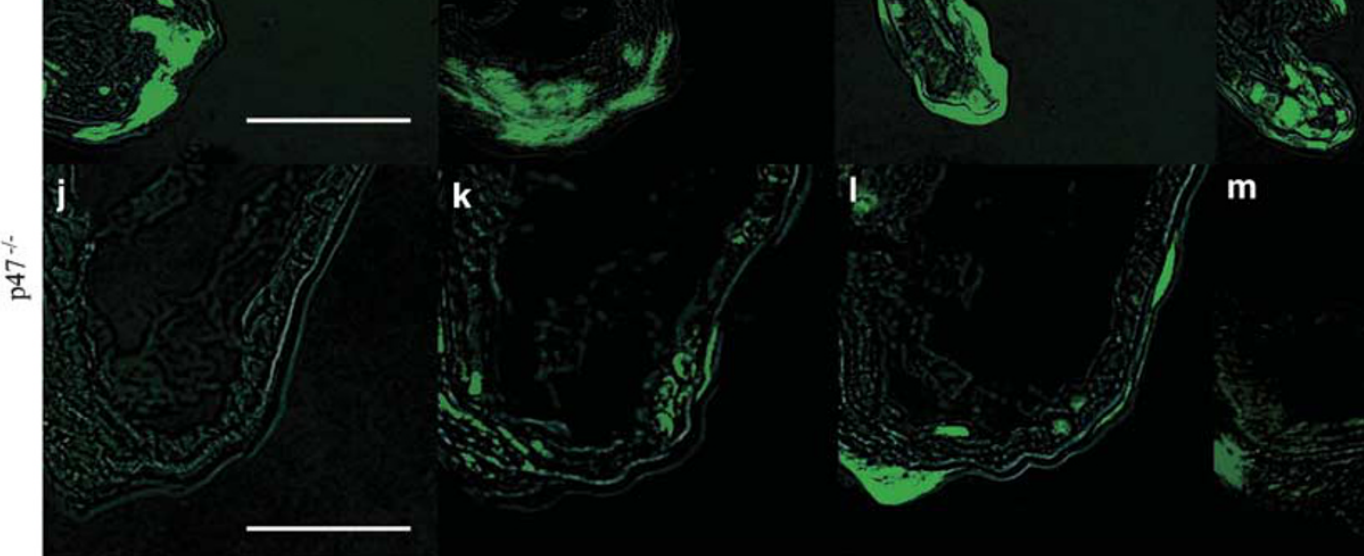

Figure 5 Aneurysm formation in p47phox knockout mice. (a) Size of induced aneurysms. Data were analyzed by the Mann-Whitney U-test. (b) Blood pressure of each mouse. Data were analyzed by the Kruskal-Wallis one-way ANOVA by ranks followed by the Tukey-Kramer test. ${ }^{* * P}<0.01$. 0 M: before

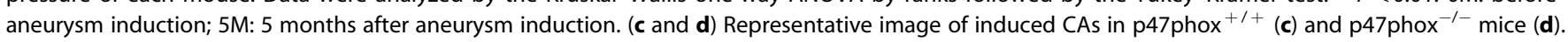
$\operatorname{Bar}=20 \mu \mathrm{m}$. (e) Macrophage infiltration in aneurysmal walls. Data were analyzed by the Mann-Whitney $U$-test. ${ }^{* * P}<0.01$. (f-m) Immunostaining of the p47phox subunit ( $\mathbf{f}$ and $\mathbf{j})$, 8-OHdG (g and $\mathbf{k})$, DNA-binding form of the NF- $\kappa$ B p65 subunit (h and $\mathbf{I})$ and MCP-1 (i and $\mathbf{m})$ in p47phox ${ }^{+/+}(\mathbf{f}-\mathbf{i})$ and p47phox ${ }^{-1-}$ mice $(\mathbf{j}-\mathbf{m})$. Bar $=20 \mu \mathrm{m}$. 

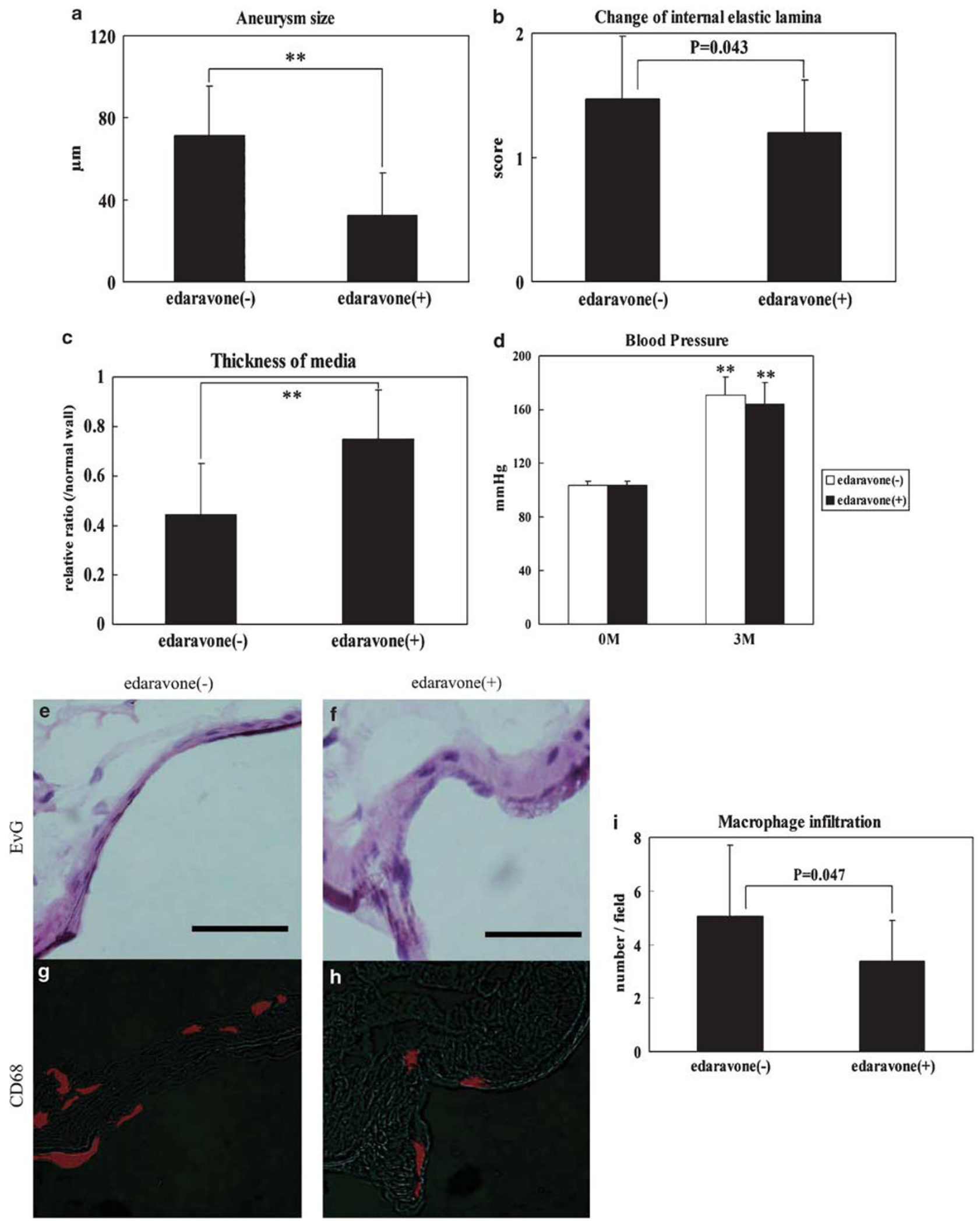

Figure 6 The effect of edaravone on CA formation in rats. (a-c) Aneurysm size: (a), changes of internal elastic lamina (b) and thickness of media (c) 3 months after aneurysm induction. Data were analyzed by the Mann-Whitney U-test. (d) Blood pressure of each rat. Data were analyzed by Kruskal-Wallis one-way ANOVA by ranks followed by the Tukey-Kramer test. ${ }^{*} \mathrm{P}<0.01 .0 \mathrm{M}$, before aneurysm induction; $3 \mathrm{M}$ : 3 months after aneurysm induction. (e-i) Macrophage infiltration into aneurysmal walls without $(\mathbf{g})$ or with $(\mathbf{h})$ edaravone treatment. (e and $\mathbf{f})$ Elastica van Gieson staining serial sections of $\mathbf{g}(\mathbf{e})$ and h (f). $B a r=30 \mu \mathrm{m}$. (i) Number of macrophages infiltrated into aneurysmal walls. Data were analyzed by the Mann-Whitney $U$-test. 

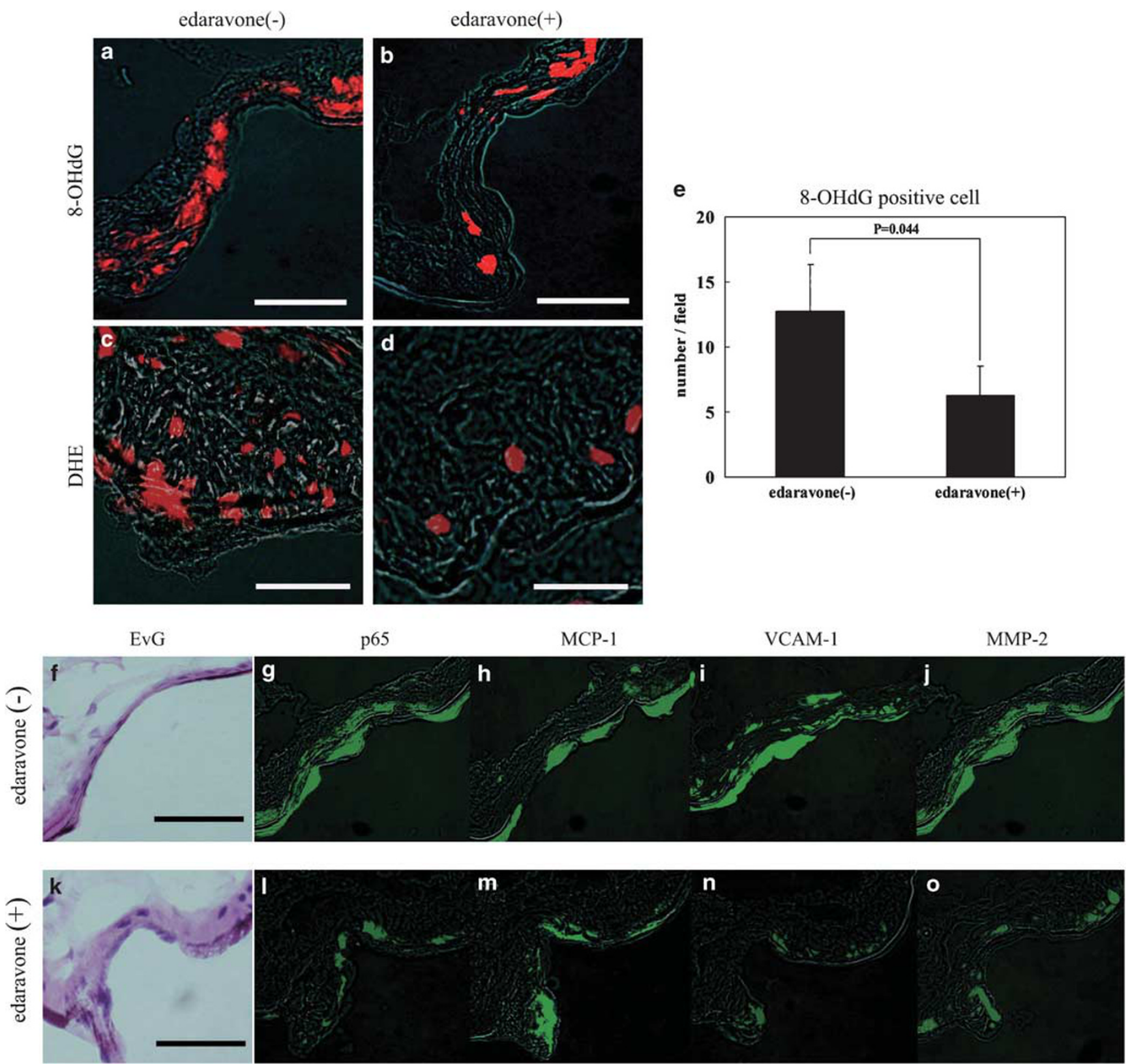

$\mathbf{n}$

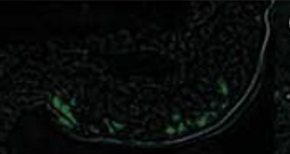

o

Figure 7 Effect of edaravone on superoxide production and inflammation-related molecule expression in the aneurysmal wall. (a-d) Immunostaining of 8OHdG ( $\mathbf{a}$ and $\mathbf{b}$ ) and in situ detection of superoxide by dihydroethidium (c and $\mathbf{d})$, without ( $\mathbf{a}$ and $\mathbf{c}$ ) or with (b and $\mathbf{d}$ ) edaravone treatment, 3 months after aneurysm induction. Bar $=30 \mu \mathrm{m}$. (e) Number of 8-OHdG-positive cells. Data were analyzed by the Mann-Whitney U-test. (f-o) Immunostaining of the DNAbinding form of the NF- $\kappa$ B p65 subunit (p65) ( $(\mathbf{g}$ and $\mathbf{~ I ) , ~ M C P - 1 ~ ( h ~ a n d ~} \mathbf{~ m}), \mathrm{VCAM}-1$ (i and $\mathbf{n})$ and MMP-2 (j and $\mathbf{o})$ without ( $\mathbf{g}-\mathbf{j})$ or with edaravone treatment (I-o) 3 months after aneurysm induction. ( $\mathbf{f}$ and $\mathbf{k}$ ) Elastica van Gieson staining (EvG) of serial sections of $\mathbf{g}(\mathbf{f})$ and $\mathbf{I}(\mathbf{k})$. Bar $=30 \mu \mathrm{m}$.

macrophage infiltration and chronic inflammation in arterial walls. $^{6}$ Inflammation-related genes upregulated in aneurysmal walls are iNOS, ${ }^{14,15} M M P,{ }^{5} M C P-1$ and VCAM-1 (unpublished data).

Reactive oxygen species is a major and critical mediator of the inflammatory cascade. ${ }^{16,17}$ It is produced through enzymatic reactions mainly by NADPH oxidase, HO-1 and iNOS. ${ }^{18,19}$ ROS production is diminished by antioxidants such as SOD-1. We previously clarified that iNOS was upregulated in aneurysmal walls and was important in CA formation, ${ }^{14,15}$ using experimentally induced CA models in rats $^{4,11}$ and mice ${ }^{13}$ that had similar pathological features to human $\mathrm{CAs}^{20}$ However, the function of ROS on CA formation remains to be elucidated. In abdominal or thoracic aortic aneurysms, ROS is abundantly produced by NADPH oxidase or iNOS and is critical on aneurysm formation by inducing inflammation in arterial walls, upregulating tissuedestructive enzymes such as MMPs, and inducing apoptosis of smooth muscle cells of the media. ${ }^{21-29}$ In the present study, we have confirmed the excessive production of ROS in 
aneurysmal walls by dihydroethidium staining or evaluation of oxidative DNA products (Figure 1). In CAs of rats, ROSproducing enzymes, NADPH p47phox, iNOS and HO-1, were upregulated in the arterial walls accompanied by decreased expression of the ROS-eliminating gene, SOD-1, resulting in the overproduction of ROS in the CA walls (Figures 2 and 3). Macrophages are major inflammatory cells in CA walls. Macrophages infiltrate the arterial walls through transcriptional upregulation of MCP-1 and VCAM-1 expression by NF- $\kappa \mathrm{B}$ activation and are important in CA progression by increasing expression of tissue-destructive MMPs or iNOS. ${ }^{6}$ Macrophages also have a close relationship with ROS production. NAPDH oxidase has several subunits. ${ }^{9,10,30}$ Among these, p47phox, which is known as neutrophil cytosol factor-1, is a subunit mainly expressed in neutrophils and macrophages. ${ }^{9,10,31,32}$ Deletion of p47phox attenuated abdominal aortic aneurysms in mice. ${ }^{28}$ The p47phox subunit of NADPH oxidase was mainly expressed in macrophages infiltrating CA walls and was upregulated during CA formation and progression (Figures 2-4). By deletion of p47phox, CA formation was markedly reduced without influencing systemic blood pressure, suggesting the importance of p47phox subunit-producing ROS in CA formation (Figure 5). Interestingly, by deletion of p47phox, macrophage infiltration by MCP-1 upregulated by NF- $\kappa \mathrm{B}$ activation, was also inhibited suggesting that macrophageproducing ROS further accumulated macrophages in CA walls. ROS is also produced by other enzymes in aneurysmal walls. To further assess the involvement of ROS in CA formation, we used the free radical scavenger edaravone in the present study. Edaravone is a widely used free radical scavenger in patients with acute cerebral infarction. ${ }^{33,34}$ Edaravone has some other potential uses in protecting against various vascular diseases including arteriosclerosis. ${ }^{35,36}$ Oral intake of edaravone $100 \mathrm{mg} / \mathrm{kg}$ per day effectively inhibited ROS production and DNA oxidation in CA walls of our rat model (Figure 7a-e). With edaravone, enlargement and medial degradation of CAs were remarkably inhibited without influencing systemic blood pressure (Figure 6a-d). Furthermore, rate of rat with no apparent degeneration in media was significantly lower in edaravone-treated group suggesting the possibility of preventive effect of edaravone against rupture (control group: 2 among 21 rats; edaravonetreated group: 7 among 10 rats; $P<0.01$ ). Edaravone, through ROS elimination, effectively inhibited the NF- $\kappa \mathrm{B}$ activation resulting in decreased expression of MCP-1, VCAM-1 and MMP-2 (Figure 7). Macrophage infiltration was significantly prevented by inhibition of MCP-1 and VCAM-1 (Figure 6e-i).

Reactive oxygen species is a major mediator of inflammation. It is excessively produced through upregulation of NADPH oxidase p47phox in macrophages, iNOS and HO1 in aneurysmal walls accompanied by decreased expression of ROS-eliminating genes. ROS is critical in CA formation through inflammatory reactions started by NF- $\kappa \mathrm{B}$ activation in the aneurysmal walls. Edaravone is one of the leading candidates for treatment of CAs in humans by elimination of ROS in aneurysmal walls.

For clinical application, CA must be regressed by medical treatment because CA is always found as a preexisting form. Because in rat or mouse model of CA, induced aneurysm is so small, today, we cannot assess the effect of Edaravone against preexisting CAs in vivo. This point is so important that it needs to be examined in future.

In the present study, we clarified the critical function of ROS in CA formation. The results of the present study provide a new insight into mechanisms of CA formation.

\section{ACKNOWLEDGEMENTS}

This work was supported by a Grant-in-Aid for Scientific Research (no. 17390399) from the Ministry of Education, Science and Culture of Japan. We thank Mitsubishi Pharma Corporation for kindly preparing us edaravone.

\section{DISCLOSURE/DUALITY OF INTEREST}

None.

1. Feigin VL, Findlay M. Advances in subarachnoid hemorrhage. Stroke 2006;37:305-308.

2. van Gijn J, Kerr RS, Rinkel GJ. Subarachnoid haemorrhage. Lancet 2007;369:306-318.

3. Wiebers DO, Whisnant JP, Huston III J, et al. Unruptured intracranial aneurysms: natural history, clinical outcome, and risks of surgical and endovascular treatment. Lancet 2003;362:103-110.

4. Hashimoto $\mathrm{N}$, Handa $\mathrm{H}$, Hazama F. Experimentally induced cerebral aneurysms in rats. Surg Neurol 1978;10:3-8.

5. Aoki $T$, Kataoka $H$, Morimoto $M$, et al. Macrophage-derived matrix metalloproteinase-2 and -9 promote the progression of cerebral aneurysms in rats. Stroke 2007;38:162-169.

6. Aoki T, Kataoka H, Shimamura M, et al. NF-kappaB is a key mediator of cerebral aneurysm formation. Circulation 2007;116:2830-2840.

7. Shatwell KP, Segal AW. NADPH oxidase. Int J Biochem Cell Biol 1996;28:1191-1195.

8. Vignais PV. The superoxide-generating NADPH oxidase: structural aspects and activation mechanism. Cell Mol Life Sci 2002;59:14281459.

9. Jones OT. The regulation of superoxide production by the NADPH oxidase of neutrophils and other mammalian cells. Bioessays 1994;16:919-923.

10. Kobayashi T, Tsunawaki S, Seguchi H. Evaluation of the process for superoxide production by NADPH oxidase in human neutrophils: evidence for cytoplasmic origin of superoxide. Redox Rep 2001;6: 27-36.

11. Nagata I, Handa $\mathrm{H}$, Hashimoto $\mathrm{N}$, et al. Experimentally induced cerebral aneurysms in rats: Part VI. Hypertension. Surg Neurol 1980;14:477-479.

12. Morimoto M, Miyamoto S, Mizoguchi A, et al. Mouse model of cerebral aneurysm-experimental induction by renal hypertension and local hemodynamic changes. Stroke 2002;33:1911-1915.

13. Aoki T, Kataoka H, Moriwaki T, et al. Role of TIMP-1 and TIMP-2 in the progression of cerebral aneurysms. Stroke 2007;38:2337-2345.

14. Fukuda S, Hashimoto N, Naritomi H, et al. Prevention of rat cerebral aneurysm formation by inhibition of nitric oxide synthase. Circulation 2000;101:2532-2538.

15. Sadamasa N, Nozaki K, Hashimoto N. Disruption of gene for inducible nitric oxide synthase reduces progression of cerebral aneurysms. Stroke 2003;34:2980-2984.

16. Winrow VR, Winyard PG, Morris $\mathrm{CJ}$, et al. Free radicals in inflammation: second messengers and mediators of tissue destruction. Br Med Bull 1993;49:506-522.

17. Griendling KK, Sorescu $D$, Ushio-Fukai $M$. NAD(P)H oxidase: role in cardiovascular biology and disease. Circ Res 2000;86:494-501.

18. Bastian NR, Hibbs Jr JB. Assembly and regulation of NADPH oxidase and nitric oxide synthase. Curr Opin Immunol 1994;6:131-139. 
19. Blokhina O, Virolainen E, Fagerstedt KV. Antioxidants, oxidative damage and oxygen deprivation stress: a review. Ann Bot (London) 2003;91:179-194.

20. Hashimoto N, Handa H, Hazama F. Experimentally induced cerebral aneurysms in rats. 3. Pathology. Surg Neurol 1979;11:299-304.

21. Khaira HS, Maxwell SR, Thomason H, et al. Antioxidant depletion during aortic aneurysm repair. Br J Surg 1996;83:401-403.

22. Miller Jr FJ, Sharp WJ, Fang $X$, et al. Oxidative stress in human abdominal aortic aneurysms: a potential mediator of aneurysmal remodeling. Arterioscler Thromb Vasc Biol 2002;22:560-565.

23. Yajima N, Masuda M, Miyazaki $M$, et al. Oxidative stress is involved in the development of experimental abdominal aortic aneurysm: a study of the transcription profile with complementary DNA microarray. J Vasc Surg 2002;36:379-385.

24. Ejiri J, Inoue N, Tsukube T, et al. Oxidative stress in the pathogenesis of thoracic aortic aneurysm: protective role of statin and angiotensin II type 1 receptor blocker. Cardiovasc Res 2003;59:988-996.

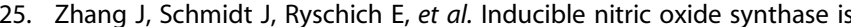
present in human abdominal aortic aneurysm and promotes oxidative vascular injury. J Vasc Surg 2003;38:360-367.

26. Dalman RL. Oxidative stress and abdominal aneurysms: how aortic hemodynamic conditions may influence AAA disease. Cardiovasc Surg 2003;11:417-419.

27. Gavrila D, Li WG, McCormick ML, et al. Vitamin E inhibits abdominal aortic aneurysm formation in angiotensin II-infused apolipoprotein Edeficient mice. Arterioscler Thromb Vasc Biol 2005;25:1671-1677.

28. Thomas M, Gavrila D, McCormick ML, et al. Deletion of p47phox attenuates angiotensin II-induced abdominal aortic aneurysm formation in apolipoprotein E-deficient mice. Circulation 2006;114:404-413.

29. McCormick ML, Gavrila D, Weintraub NL. Role of oxidative stress in the pathogenesis of abdominal aortic aneurysms. Arterioscler Thromb Vasc Biol 2007;27:461-469.

30. Sumimoto H, Miyano K, Takeya R. Molecular composition and regulation of the Nox family $\mathrm{NAD}(\mathrm{P}) \mathrm{H}$ oxidases. Biochem Biophys Res Commun 2005;338:677-686.

31. Green SP, Hamilton JA, Uhlinger DJ, et al. Expression of p47-phox and p67-phox proteins in murine bone marrow-derived macrophages: enhancement by lipopolysaccharide and tumor necrosis factor alpha but not colony stimulating factor 1. J Leukoc Biol 1994;55:530-535.

32. Barbieri SS, Eligini S, Brambilla $M$, et al. Reactive oxygen species mediate cyclooxygenase- 2 induction during monocyte to macrophage differentiation: critical role of NADPH oxidase. Cardiovasc Res 2003;60:187-197.

33. Watanabe T, Morita I, Nishi $\mathrm{H}$, et al. Preventive effect of $\mathrm{MCl}-186$ on 15-HPETE induced vascular endothelial cell injury in vitro. Prostaglandins Leukot Essent Fatty Acids 1988;33:81-87.

34. Watanabe T, Yuki S, Egawa M, et al. Protective effects of $\mathrm{MCl}-186$ on cerebral ischemia: possible involvement of free radical scavenging and antioxidant actions. J Pharmacol Exp Ther 1994;268:1597-1604.

35. Mikawa K, Akamatsu H, Nishina K, et al. Effects of edaravone on human neutrophil function. Acta Anaesthesiol Scand 2005;49:385-389.

36. Xi H, Akishita $M$, Nagai $K$, et al. Potent free radical scavenger, edaravone, suppresses oxidative stress-induced endothelial damage and early atherosclerosis. Atherosclerosis 2007;191:281-289. 